\title{
RANCANG BANGUN ALAT PEREKAM DATA LIKUIFAKSI BERBASIS ARDUINO NANO
}

\author{
Rizana Fauzi, Aidynal Mustari \\ Fakultas Teknik, Jurusan Teknik Elektro, Universitas Tadulako \\ email : rfauzi86@gmail.com
}

\begin{abstract}
Central Sulawesi, precisely in the city of Palu, is one of the areas that frequently occurs in earthquakes and has high seismicity. The regional geology of the Palu area and its surroundings is dominated by quarterly deposits consisting of fluivatil and alluvium deposits. These natural conditions have several potentials that are detrimental, including the potential for liquidity. (Widyaningrum, 2012).

Liquidation is an event that occurs when a soil becomes saturated or loses its ability to support the mass above it because the land changes form into heavy water or becomes liquid. Lack of further knowledge about the faction by the surrounding community causes a lack of vigilance in dealing with the faction.

The things that people need to know about potentially liquefaction soils are data on soil moisture, changes in underground temperature, and vibrations that are felt underground when earthquakes occur shortly after liquefaction using a device in the form of an arduino nano-based data recorder. The Design of Arduino Nano Based Likuefaction Data Recording Tool can be used to record and record data on lycufaction disaster events. And is used to make it easier to analyze the potential occurrence of liquefaction in certain regions by utilizing the sensor to measure soil temperature, soil moisture, and vibrations that occur in the soil.
\end{abstract}

\section{PENDAHULUAN}

Berdasarkan letak geografisnya, Indonesia merupakan salah satu wilayah dengan potensi bencana besar seperti gempa bumi dan tsunami dengan intensitas yang cukup tinggi karena Indonesia dijuluki sebagai Ring of Fire. Hal tersebut dikarenakan Indonesia dikelilingi oleh banyak gunung berapi. Indonesia dilalui beberapa sesar besar di dunia. Banyaknya sesar aktif di Indonesia mengakibatkan tingkat bencana di
Indonesia sangatlah tinggi. Jalur yang dilalui oleh sesar aktif berada pada pulau Jawa, Maluku, serta Sulawesi.

Sulawesi Tengah, tepatnya di Kota Palu merupakan salah satu daerah yang sering terjadi gempa dan mempunyai seismisitas tinggi. Geologi regional daerah Palu dan sekitarnya didominasi oleh endapan kuarter yang terdiri atas endapan fluivatil dan alluvium. Kondisi alam tersebut memiliki beberapa potensi yang merugikan diantaranya adalah potensi likuefaksi. (Widyaningrum, 2012)

Likuefaksi adalah sebuah pertistiwa yang terjadi ketika sebuah tanah menjadi jenuh atau kehilangan kemampuannya untuk menopang massa diatasnya karena tanah berubah wujud menjadi air berat atau menjadi cairan. Likuefaksi terjadi ketika adanya sebuah tegangan seperti gempa bumi atau perubahan ketegangan secara mendadak yang melintasi seismisitas pada kondisi tanah tertentu.

Dari sejumlah catatan kejadian likuefaksi yang pernah terjadi, diketahui bahwa peristiwa likuefaksi lebih berpotensi terjadi pada konsistensi tanah granular jenuh yang lepas dengan sifat drainase di dalam tanah yang buruk. Deposit tanah yang berpotensi terlikuefaksi pada saat terjadinya gempa adalah pasir halus, pasir berlumpur, dan pasir biasa. Apabila beban siklik terjadi seperti saat gempa bumi, pasir lepas cenderung mengalami penurunan volume, hal ini mengakibatkan terjadinya peningkatan kenaikan air pori dan penurunan kekuatan geseran efektif tanah.

Hal ini sangat buruk karena merusak infrastuktur sehingga sangat penting untuk mengetahui data-data agar dapat dikaji lebih lanjut mengenai pengetahuan likuefaksi pada suatu daerah 
terutama Palu, Sulawesi Tengah dan sekitarnya guna perencanaan tata ruang serta membangun infrastruktur yang lebih baik.

Kurangnya pengetahuan lebih
lanjut mengenai likuefaksi oleh
masyarakat sekitar menyebabkan
kurangnya kewaspadaan dalam
menghadapi likuefaksi. Hal-hal yang
perlu diketahui oleh masyarakat mengenai
tanah berpotensi likuefaksi adalah data-
data mengenai kelembapan tanah,
perubahan suhu bawah tanah, serta
getaran yang terasa dibawah tanah ketika
gempa bumi terjadi sesaat setelah
likuefaksi dengan menggunakan alat
berupa perekam data berbasis arduino
nano.

Rancang bangun alat perekam data berbasis arduino nano berfungsi untuk membantu masyarakat dalam mengetahui rekam jejak data pada saat terjadi likuefaksi melalui sensor-sensor yang telah terpasang. Rancang bangun perekam data berbasis arduino nano juga akan mencatat serta menyimpan data setelah terjadi bencana likuefaksi. Data-data tersebut akan disimpan pada arduino nano yang terhubung, lalu akan memberikan tanda kepada masyarakat berupa cahaya dari warna lampu yang berbeda-beda serta bunyi buzzer sesuai dengan keras getaran yang terjadi.

Dengan menganalisis data-data likuefaksi dapat membantu meminimalisir korban jiwa dalam peristiwa tersebut. Analisis data tersebut juga diperlukan sebagai pembanding dengan data-data yang telah tercatat sebelumnya. Data yang tercatat pada alat tersebut bisa disimpan serta dipelajari lebih lanjut untuk penanganan masalah mengenai bencana likuefaksi.

Berdasarkan uraian masalah pada latar belakang di atas, maka yang menjadi perumusan masalah adalah sebagai berikut:

a. Apa yang dimaksud dengan rancang bangun alat perekam data likuefaksi berbasis arduino nano? b. Bagaimana penerapan rancang bangun alat perekam data likuefaksi berbasis arduino nano dalam skala simulator?

c. Apakah rancang bangun alat perekam data likuefaksi berbasis arduino nano dapat berfungsi dengan efektif pada sebuah simulator likuefaksi? adalah:

Adapun tujuan dari penelitian ini

a. Untuk mengetahui lebih lanjut mengenai rancang bangun alat perekam data likuefaksi berbasis arduino nano.

b. Untuk mengetahui penerapan rancang bangun alat perekam data likuefaksi berbasis arduino nano dalam skala simulator likuefaksi.

c. Untuk mengetahui jika rancang bangun alat perekam data likuefaksi berbasis arduino nano dapat berfungsi secara efektif pada sebuah simulator likuefaksi.

Penelitian mengenai rancang bangun alat perekam data likuefaksi berbasis arduino nano belum pernah diteliti sebelumnya, namun banyak penelitian yang telah membahas rancang bangun berbasis arduino, salah satunya adalah penelitian oleh Lufiyana, dkk yang berjudul Rancang Bangun Alat Pengukur Suhu Tanah, Kelembapan Tanah, dan Resistansi. Pada penelitian tersebut alat yang digunakan berbasis arduino uno dan rancang bangun alat tersebut diuji keefektifannya pada tiga jenis tanah yang berbeda. Hasilnya adalah rancang bangun alat tersebut dapat berfungsi dengan baik saat diuji di tiga jenis tanah yang berbeda.

Penelitian mengenai rancang bangun alat pengukur suhu tanah, kelembapan tanah, dan resistansi tanah berfungsi cukup efektif pada tanah secara umum tetapi melihat kondisi sekarang, tepatnya di Sulawesi Tengah mengenai bencana likuefaksi sangat menarik untuk diteliti lebih lanjut dan dibutuhkannya pencatatan data yang tepat setelah bencana itu terjadi. 


\section{TINJAUAN PUSTAKA}

\subsection{LIKUEFAKSI}

Menurut Kamus Besar Bahasa Indonesia, Likuefaksi merupakan fenomena hilangnya kekuatan lapisan tanah akibat beban getaran gempa. Sementara itu, menurut (Christian Vicky Delfis Lonteng, 2013) likuefaksi merupakan kegagalan struktur akibat hilangnya kestabilan tanah pada saat gempa biasanya terjadi pada tanah pasir yang bersifat jenuh dan memiliki gradasi yang seragam.

Liquefaction-the sudden loss of strength of a mass of water-saturated sediment-was disclay. One type of quickclay was formed originally from clay minerals that accumulated in salt water. The ions in the salty pore waters held clay minerals together as aggregates, forming an open "house-ofcards" structure. (Ludman, 1993)

Likuefaksi terjadi pada tanah yang berpasir, tidak terlalu padat, dan memiliki elevasi air tanah yang lebih tinggi atau jenuh air. Saat normal, tanah yang berpasir akan saling bersinggungan dan mengunci sehingga kondisi tanah masih stabil. Saat gempa terjadi, tanah tersebut akan terisi oleh air pada ruang antar partikelnya sehingga kekuatan saling mengunci pada partikel tanah menghilang dan likuefaksi pun terjadi. (Proses likuefaksi dapat dilihat pada lampiran 1)

Likuefaksi yang terjadi sesaat setelah gempa berkekuatan 7,4 SR menghantam wilayah tersebut pada Jumat petang tanggal 28 September 2018 yang lalu menggeser tanah dari Desa Jono Oge ke Desa Langeleso yang berjarak kurang lebih 3 kilometer. Sebagian besar wilayah di Dusun 3, Desa Langaleso tersebut rata dengan tanah. Pohon-pohon, menara seluler hanyut dan bergeser, demikian pula dengan rumah-rumah penduduk, bangunan masjid dan gereja, Desa Balaroa, Petobo, serta Bone Oge menjadi beberapa desa lainnya yang terkena dampak likuefaksi. Likuefaksi yang terjadi di daerah tersebut terlihat seperti lumpur yang di gulung-gulung, pemukiman warga menjadi sasaran atas bencana ini, bahkan ada beberapa warga yang menjadi korban dari likuefaksi tersebut. (Khairunnisa, 2018) (Lampiran 2, 3, dan 4)

Menurut Abdullah

likuefaksi pada tanggal 28 September lalu di wilayah Petob, Sulawesi Tengah terjadi karena adanya guncangan keras akibat gempa bumi sebesar 7,4 SR yang mengakibatkan air yang mengalir di sekitar akuifer bergerak keatas dan terjadinya pembuburan pada tanah. Jika terdapat bangunan bermassa besar diatasnya maka bangunan diatas tanah likuefaksi akan turun kebawah dan tanah akan menggelembung.

Akuifer merupakan lapisan bawah tanah yang memiliki porositas tinggi serta bersifat permeable atau dengan kata lain akuifer adalah lapisan bawah tanah yang mengandung dan mampu membawa air tanah karena adanya pori pada lapisan tanah tersebut sehingga terdapat ruang antar butir tanah yang mampu mengalirkan air dengan baik. Contoh lapisan tanah akuifer adalah pasir, kerikil, dan batu pasir. Ketebalan akuifer dapat ditentukan dari jarak permukaan air tanah (water table) sampai pada lapisan semi kedap air (impermeable) yaitu aquiclude dan aquifuge.

Likuefaksi dapat menyebabkan kejadian seperti penurunan cepat (Quick settlement), miringnya pondasi bangunan (tilting), atau penurunan sebagian (differential settlement). Perpindahan lateral dan penurunan juga dapat menjadi efek likuefaksi di bidang konstruksi.

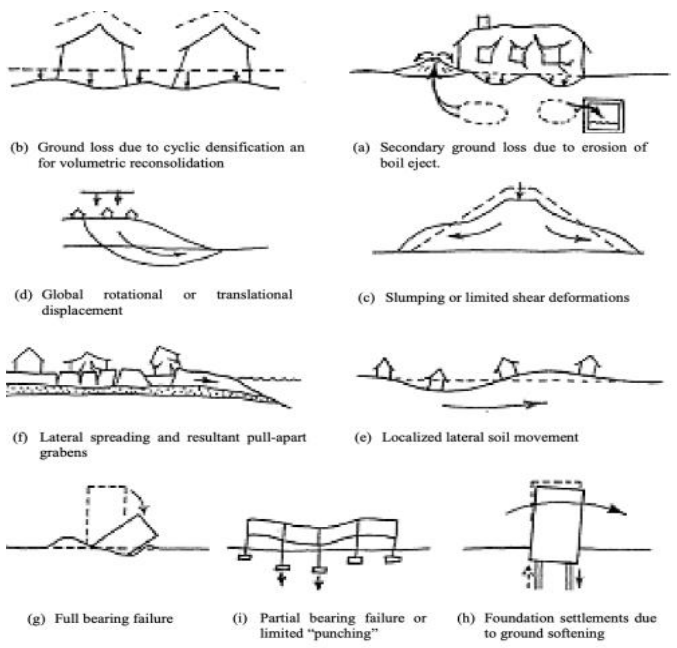


Proses penurunan terbagi menjadi sembilan seperti disajikan pada gambar 2.1 oleh Zhang, drr 1998 dalam Seed, drr 2001 sedangkan proses perpindahan terbagi menjadi tiga seperti disajikan pada Gambar 2.2 (Seed, 2001)

Gambar 2.1: Proses penurunan lateral tanah

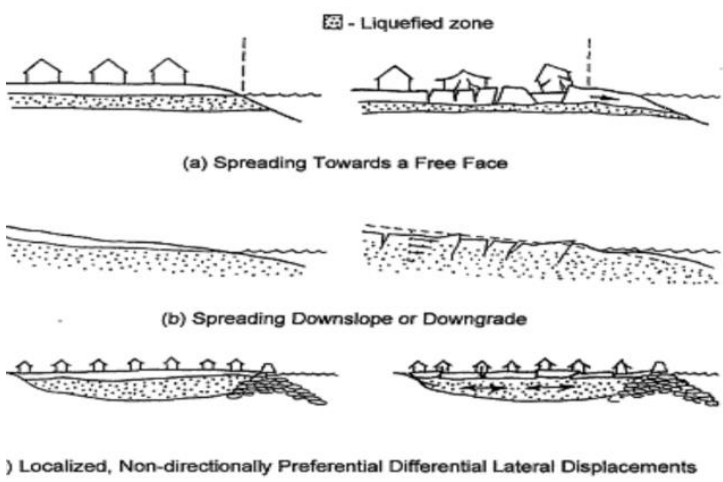

Gambar 2.2: Proses perpindahan lateral tanah

\subsection{ARDUINO NANO}

Arduino merupakan platform dari physical computing yang bersifat open source, baik untuk hardware maupun softwarenya. Papan arduino terdiri dari beberapa macam, salah satunya adalah arduino nano yaitu papan arduino terkecil, menggunakan mikrokontroler Atmega 328 untuk Arduino Nano 3.x dan Atmega168 untuk Arduino Nano 2.x. Arduino Nano tidak dilengkapi dengan soket catudaya, tetapi terdapat pin untuk catu daya luar atau dapat menggunakan catu daya dari mini USB port. Arduino Nano didesain dan diproduksi oleh Gravitech.

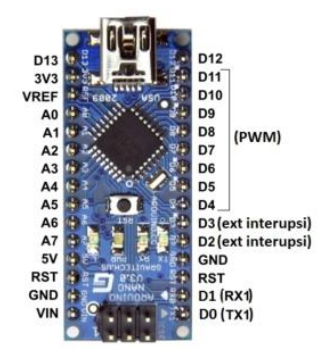

Gambar 2.3: Bentuk fisik arduino nano

(https://djukarna4arduino.wordpress.com/2015/01/ 19/arduino-nano/)

\subsection{SENSOR SUHU}

Sensor suhu sangat dibutuhkan pada rancang bangun pencatat data likuefaksi berbasis arduino nano guna mengakumulasi dan mencatat data jika sewaktu-waktu terjadi likuefaksi dan dapat dibandingkan dengan data-data likuefaksi lainnya. Pengukuran suhu tanah dapat menggunakan sensor DS18B20 waterproof. Sensor DS18B20 waterproof merupakan sensor temperatur digital yang dapat dihubungkan dengan mikrometer lewat antarmuka 1-Wire [11]. Sensor DS18B20 memiliki akurasi yang lebih baik dibanding sensor lainnya. (Lufiyana, 2017) Gambar 2.4 dan Tabel 2.1

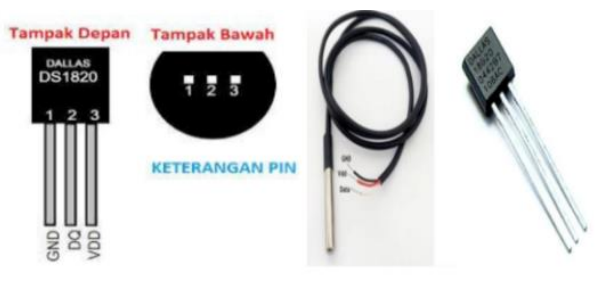

Gambar 2.4: Bentuk fisik sensor suhu DS18B20 (Akbar, 2017)

Keterangan antarmuka:

- Kabel merah: VDD

- Kabel hitam: GND

- Kabel kuning: DQ

Tabel 2.1: Deskripsi pin DS18B20

\begin{tabular}{|c|c|c|}
\hline PIN & Nama & Fungsi \\
\hline 1 & GND & Ground \\
\hline 2 & DQ & $\begin{array}{c}\text { Data } \\
\text { inputloutput }\end{array}$ \\
\hline 3 & VDD & $\begin{array}{c}\text { Tegangan } \\
\text { sensor }\end{array}$ \\
\hline
\end{tabular}

\subsection{SENSOR KELEMBAPAN}

Sensor kelembapan tanah merupakan sensor yang digunakan untuk mengetahui intensitas air pada tanah, jenis sensor untuk mengukur kelembapan tanah yang akan digunakan pada rancang bangun ini adalah YL-69 yang terdiri atas dua probe yaitu untuk melewatkan arus melalui tanah, kemudian membaca 
resistansinya untuk mengetahui nilai kelembapan. Sensor kelembapan YL-69 dapat membaca kadar air dalam 3 kondisi yaitu:

- 0-300: tanah basah (di dalam air)

- 300-700: tanah lembab

- 700-950: tanah kering atau udara bebas

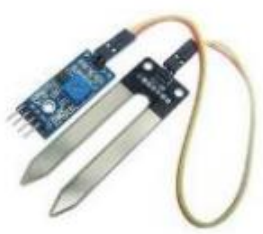

Gambar 2.5: Bentuk fisik sensor kelembapan YL-69 (Wijaya, 2017)

\subsection{SENSOR GETAR}

Merupakan sensor yang digunakan untuk mengukur getaran suatu benda. Salah satu sensor getar yang biasanya digunakan adalah accelelometer yaitu dengan menghitung percepatan suatu benda berdasarkan pergerakan benda yang dihubungkan dengan perubahan massa pada benda tersebut. Sensor getar yang akan digunakan adalah SW-420.

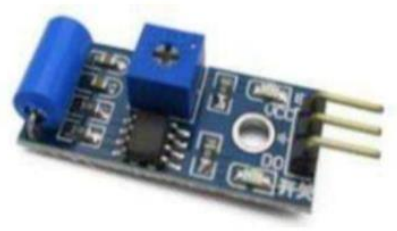

Gambar 2.6: Sensor getar SW-420

(Najmurrokhman, 2018)

\subsection{LCD 16x2}

Merupakan sebuah alat yang berfungsi untuk menampilkan suatu ukuran besaran atau angka, sehingga dapat di lihat dan diketahui melalui tampilan layar kristalnya. Dimana penggunaan LCD dalam alat pendeteksi likuefaksi ini menggunakan LCD dengan 16x2 karakter (2 baris 16 karakter). LCD 16x2 memiliki 16 nomor pin, dimana masing-masing pin memiliki tanda simbol dan juga fungsi-fungsinya. LCD 16x2 ini beroperasi pada power supply $+5 \mathrm{~V}$, tetapi juga dapat beroperasi pada power supply +3 V. (Budiyanto, 2012)

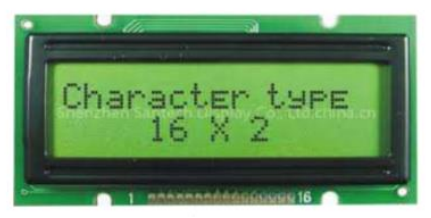

Gambar 2.7: LCD 16x2 (Sinaulan, 2015)

\subsection{BATERAI LI-PO (LITHIUM POLIMER)}

Baterai lithium polimer merupakan baterai yang bisa diisi ulang dan memiliki bobot lebih ringan dibanding baterai lain serta memiliki banyak bentuk dan ukuran, baterai li-po ini dirancang untuk pemakaian lebih lama karena bersifat non-removeable yaitu tidak dapat dilepas atau ditukar. Baterai ini juga memiliki tingkat keamanan yang baik pada kondisi temperatur tinggi sehingga risiko terjadinya ledakan menjadi lebih kecil.

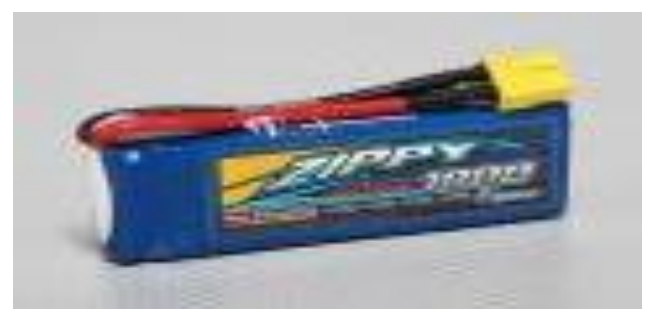

Gambar 2.8: Bentuk fisik baterai Li-Po

(Sumber : http://ishadyhobbyaero.com/productdetail/723/zippy-flightmax-2s1800mah-40c.html)

\section{METODE PENELITIAN}

\subsection{PENGUMPULAN DATA}

Penelitian akan dilakukan pada tanggal 1-30 Juni 2019 berlokasi di SMA Al-Azhar Mandiri Palu. Pada bagian pengumpulan data akan dilakukan dalam tiga tahap. Pertama-tama yaitu dengan 
melakukan wawancara kepada masyarakat setempat yang selamat dari bencana likuefaksi guna mengetahui kondisi tanah disaat likuefaksi terjadi. Setelah itu akan dilakukannya observasi yaitu dengan melihat proses terjadinya likuefaksi melalui sebuah ilustrasi. Terakhir adalah dengan membaca studi literatur dan mempelajari jurnal serta referensi yang ada.

\subsection{PERANCANGAN ALAT}

\section{ALAT:}
a. Akuarium
b. Tanah 5
c. Motor dc
d. Air

BAHAN:

1. Arduino Nano

2. Sensor Suhu DS18B20

3. Sensor kelembapan tanah YL69

4. Sensor Getar

5. LCD ( Liquid Crystal Display ) $16 \times 2$

6. Baterai Li-Po

7. LED (Merah, kuning, hijau)

8. Buzzer

CARA KERJA:

Pada penelitian ini, untuk melihat cara kerja alat ini akan dilakukan dalam 5L tanah dan dengan getaran yang konstan pada lima kali percobaan:

1. Sensor getar, sensor kelembapan dan sensor suhu ditanam kedalam tanah.

2. Ketika getaran terdeteksi, sensor kelembapan dan sensor suhu akan menerima data berupa kelembapan dan suhu tanah.

3. Data dari 3 sensor tersebut akan diolah ke mikrokontroler arduino nano untuk dikalkulasikan.

4. Dari arduino nano akan menampilkan data tersebut ke LCD serta menyalakan LED dan membunyikan buzzer sebagai mitigasi dini.

\section{PENGUMPULAN DATA}

Pengujian alat akan dilakukan dalam lima tahap yang meliput pengujian tingkat suhu lalu pengujian tingkat kelembapan dan volume air tanah serta akan mengukur penurunan tanah yang terjadi pada kelima tahap tersebut seperti yang akan dicatat dalam rancangan tabel dan grafik berikut:

Tabel 3.1: Desain Tabel Hasil pengukuran volume air, waktu, penurunan tanah, suhu, dan nilai

\begin{tabular}{|c|c|c|c|c|c|}
\hline \multicolumn{6}{|c|}{ kelembapan } \\
\hline $\begin{array}{c}\text { Tah } \\
\text { ap }\end{array}$ & $\begin{array}{c}\text { Volu } \\
\text { me } \\
\text { Air } \\
(\mathrm{mL})\end{array}$ & $\begin{array}{l}\text { Wa } \\
\text { ktu } \\
\text { (s) }\end{array}$ & $\begin{array}{l}\text { Penuru } \\
\text { nan } \\
\text { Tanah } \\
\text { (cm) }\end{array}$ & $\begin{array}{c}\mathrm{Su} \\
\mathrm{hu} \\
\left({ }^{\circ} \mathrm{C}\right. \\
)\end{array}$ & $\begin{array}{c}\text { Kelemb } \\
\text { apan }\end{array}$ \\
\hline & & & & & \\
\hline & & & & & \\
\hline & & & & & \\
\hline & & & & & \\
\hline & & & & & \\
\hline
\end{tabular}

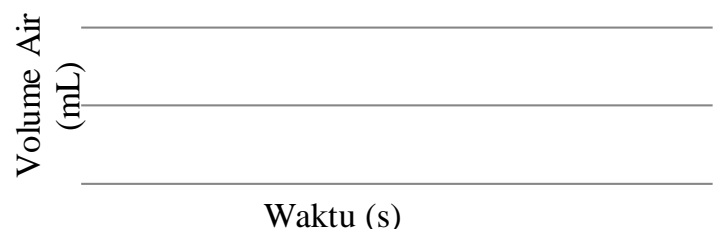

Gambar 3.1: Desain grafik Pengaruh waktu (s) terhadap volume air $(\mathrm{mL})$

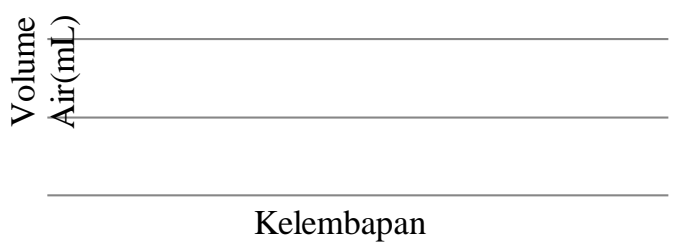

Gambar 3.2: Desain grafik Pengaruh waktu (s) terhadap nilai kelembapan tanah pada ADC 
苂

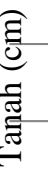

Gambar3.3: Waktu (s) $\quad$ Desain grafik

Pengaruh waktu (s) terhadap penurunan tanah $(\mathrm{cm})$

\section{苂远}

Kelembapan

Gambar 3.4: Desain grafik Pengaruh nilai kelembapan pada ADC terhadap penurunan tanah $(\mathrm{cm})$

\section{HASIL DAN PEMBAHASAN}

\subsection{DESKRIPSI ALAT:}

Alat tersebut terdiri dari beberapa komponen, yaitu:

1. Arduino: sebagai penghubung semua komponen juga sebagai pusat pengolahan data dan kalkulasi

2. Sensor: komponen yang berfungsi sebagai penerima data yang akan diolah oleh Arduino. Sensor pada alat ini terdiri dari:

a. Sensor Getar: sebagai pendeteksi getaran atau dalam penelitian ini diasumsikan sebagai gempa. Dalam hal ini jenis sensor yang digunakan ialah Sensor "SW-420"

b. Sensor Suhu: sebagai pengukur nilai suhu tanah.

c. Sensor kelembapan: sebagai pengukur nilai kelembapan tanah. Dalam hal ini sensor yang digunakan ialah sensor "Soil Moisture". Nilai yang dihasilkan berupa nilai tegangan analog yang kemudian akan dikoversi oleh mikrokontroller melalui pin ADC (Analog Digital Converter). d. Data analog yang sudah terkonversi akan ditampilkan dalam bentuk data digital pada mikrokontroller.

3. LED (Light Emitting Diode): komponen yang menghasilkan sebuah cahaya apabila dialiri arus listrik (seperti lampu).

4. Buzzer: komponen yang menghasilkan sebuah bunyi apabila dialiri arus listrik. Buzzer juga akan berbunyi ketika getaran/gempa terdeteksi. Cahaya LED dan bunyi Buzzer berfungsi sebagai mitigasi dini.

5. LCD (Liquid Crystal Display): komponen ini berfungsi menampilkan data dari sensor suhu dan kelembaban yang telah diolah/dikalkulasikan dalam program arduino.

6. Power Suplay menggunakan baterai lithium polimer (lipho) dengan rangkaian regulator tegangan $5 \mathrm{~V}$. Rangkaian ini berfungsi sebagai pengatur tegangan, karena rangkaian utama (arduino dan sensor) merupakan rangkaian yang hanya dapat di aktifkan dengan sumber tegangan antara 3,5 V sampai $6 \mathrm{~V}$, maka dibutuhkan komponen tambahan untuk dapat menurunkan nilai tegangan dari baterai lipho yang besarnya $12 \mathrm{~V}$ menjadi $5 \mathrm{~V}$ agar aman digunakan pada rangkaian.

7. Cashing (box alat) merupakan tempat untuk menaruh rangkaian agar lebih terlihat baik dan aman dari kerusakan. Cashing terbuat dari akrilik setebal 5 $\mathrm{mm}$ berwarna hitam dan dibentuk menyerupai kotak persegi dengan sensor getar, sensor kelembapan dan sensor suhu diletakkan di luar kotak, sedangkan rangkaian terpasang di dalam kotak dan terhubung dengan kabel. LCD terpampang pada bagian depan kotak sebagai penampil data digital dari sensor. 


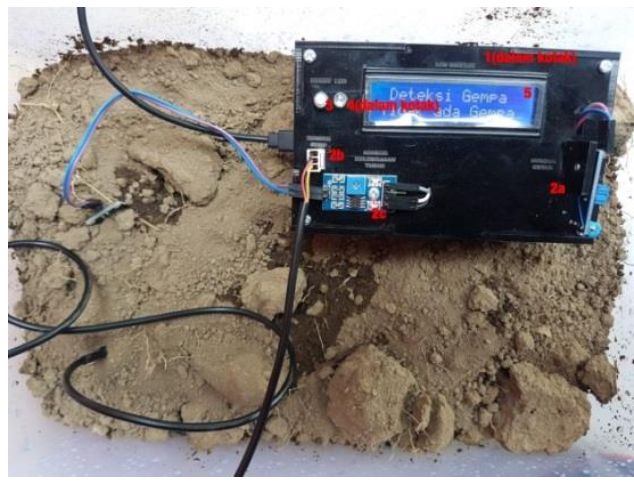

Gambar 4.4: Deskripsi letak komponen pada alat

\subsection{PRINSIP KERJA ALAT:}

Prinsip kerja alat dapat dilihat dari flowchart atau diagram alir di bawah ini:

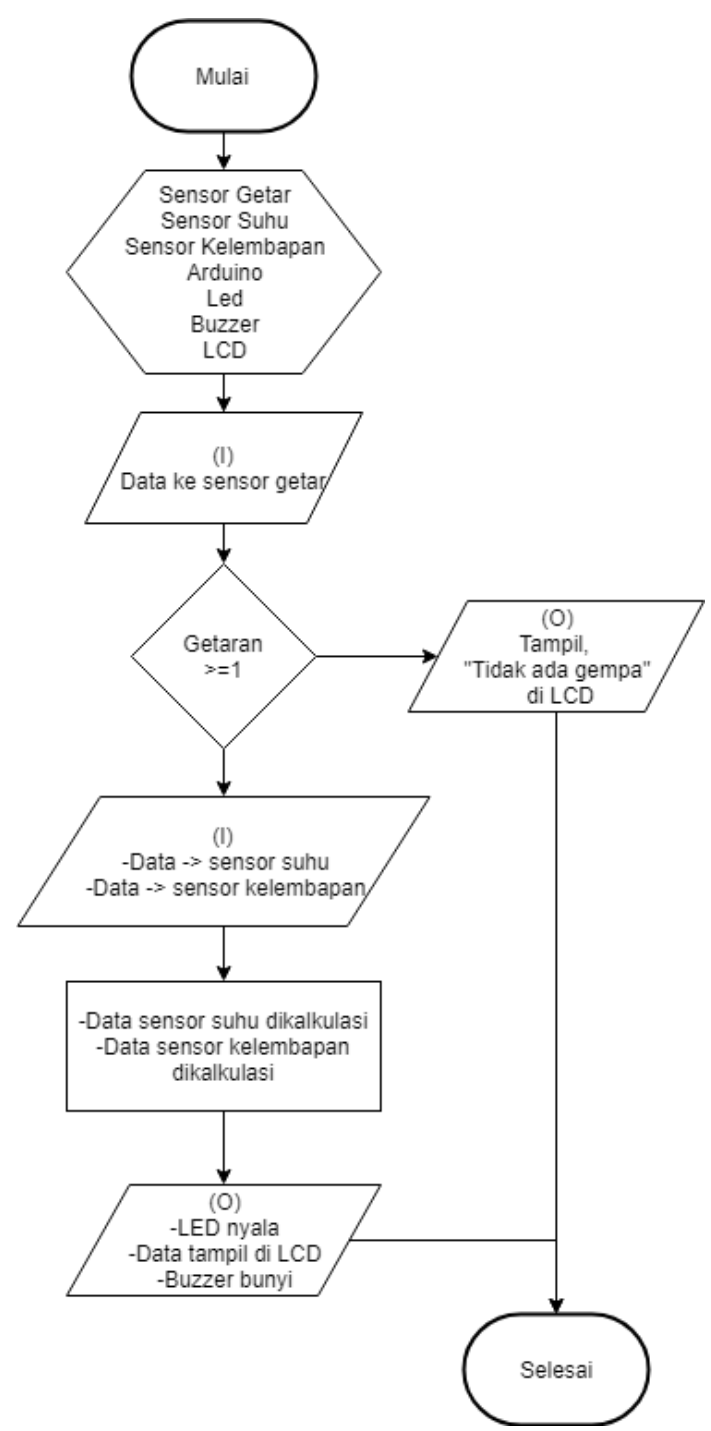

1. Sensor getar, suhu, dan kelembapan, LED, buzzer, serta LCD terhubung pada arduino

2. Sensor getar sebagai acuan untuk berfungsinya sensor suhu dan kelembaban serta LED dan buzzer

3. ketika getar terdeksi, maka sensor kelembapan dan suhu berfungsi menerima data dan akan terkirim ke arduino serta cahaya LED menyala dan buzzer berbunyi

4. data sensor suhu akan dikalkulasikan oleh arduino dalam bentuk satuan suhu yaitu derajat Celcius $\left({ }^{\circ} \mathrm{C}\right)$

5. Data sensor suhu yang sudah terkalkulasikan dan data kelembapan akan tampil di LCD.

6. Ketika getar tidak terdeteksi maka yang akan tampil di LCD adalah "Tidak ada gempa". 
Hasil Pengambilan Data uji nilai tegangan output pada sensor kelembapan.

Pada pengujian ini dilakukan dengan mengukur output dari sensor kelmbapan dengan alat ukur tegangan (AVO meter). Kemudian dilihat berapa nilai tegangan yang terbaca pada alat ukur dalam kondisi tanah kering dan kondisi tanah basah serta kondisi basah. Ada delapan (8) tahapan dalam pengukuran yang mengacu pada tingkat kedalaman probe yang tertanam pada media tanah atau air.

Tabel 4.1: Data hasil pengukuran keluaran tegangan

\begin{tabular}{|c|c|c|c|}
\hline Tahap & $\begin{array}{c}\text { Tanah } \\
\text { kering } \\
\text { (Volt) }\end{array}$ & $\begin{array}{c}\text { Tanah basah } \\
\text { (Volt) }\end{array}$ & Air (Volt) \\
\hline 1 & 4,53 & 1,56 & 2,64 \\
\hline 2 & 4,32 & 1,04 & 1,94 \\
\hline 3 & 2,79 & 0,96 & 1,87 \\
\hline 4 & 2,41 & 0,94 & 1,71 \\
\hline 5 & 2,04 & 0,75 & 1,65 \\
\hline 6 & 1,62 & 0,65 & 1,59 \\
\hline 7 & 1,32 & 0,57 & 1,41 \\
\hline 8 & 1,02 & 0,49 & 1,30 \\
\hline
\end{tabular}

Dari tabel 4.1, dapat dilihat bahwa nilai output tegangan dari sensor berbeda-beda pada kondisi tanah kering, tanah basah dan air. Nilai tegangan output sensor pada tanah kering lebih tinggi dibandingkan nilai tegangan output sensor pada tanah basah.

Tabel 4.2: Hasil pengukuran volume air, waktu likuefaksi, penurunan tanah, suhu, dan nilai

\begin{tabular}{|c|c|c|c|c|c|}
\hline $\begin{array}{c}\text { Tah } \\
\text { ap }\end{array}$ & $\begin{array}{c}\text { Volu } \\
\text { me } \\
\text { Air } \\
(\mathrm{mL})\end{array}$ & $\begin{array}{c}\text { Waktu } \\
\text { Likuef } \\
\text { aksi (s) }\end{array}$ & $\begin{array}{c}\text { Penuru } \\
\text { nan } \\
\text { Tanah } \\
(\mathrm{cm})\end{array}$ & $\begin{array}{c}\text { Suhu } \\
\left({ }^{\circ} \mathrm{C}\right)\end{array}$ & $\begin{array}{c}\text { Kelemb } \\
\text { apan }\end{array}$ \\
\hline 1 & $\begin{array}{c}1000 \\
\mathrm{~mL}\end{array}$ & $60 \mathrm{~s}$ & $2 \mathrm{~cm}$ & $\begin{array}{c}29,1 \\
2^{\circ} \mathrm{C}\end{array}$ & 210 \\
\hline 2 & $\begin{array}{c}1500 \\
\mathrm{~mL}\end{array}$ & $30 \mathrm{~s}$ & $3,8 \mathrm{~cm}$ & $\begin{array}{c}28,8 \\
7^{\circ} \mathrm{C}\end{array}$ & 243 \\
\hline 3 & $\begin{array}{c}2000 \\
\mathrm{~mL}\end{array}$ & $12 \mathrm{~s}$ & $4,5 \mathrm{~cm}$ & $\begin{array}{c}28,8 \\
9^{\circ} \mathrm{C}\end{array}$ & 283 \\
\hline 4 & $\begin{array}{c}2500 \\
\mathrm{~mL}\end{array}$ & $10 \mathrm{~s}$ & $5,2 \mathrm{~cm}$ & $\begin{array}{c}30,6 \\
{ }^{\circ} \mathrm{C}\end{array}$ & 272 \\
\hline 5 & $\begin{array}{c}3000 \\
\mathrm{~mL}\end{array}$ & $3 \mathrm{~s}$ & $6 \mathrm{~cm}$ & $\begin{array}{c}31,3 \\
{ }^{\circ} \mathrm{C}\end{array}$ & 290 \\
\hline
\end{tabular}

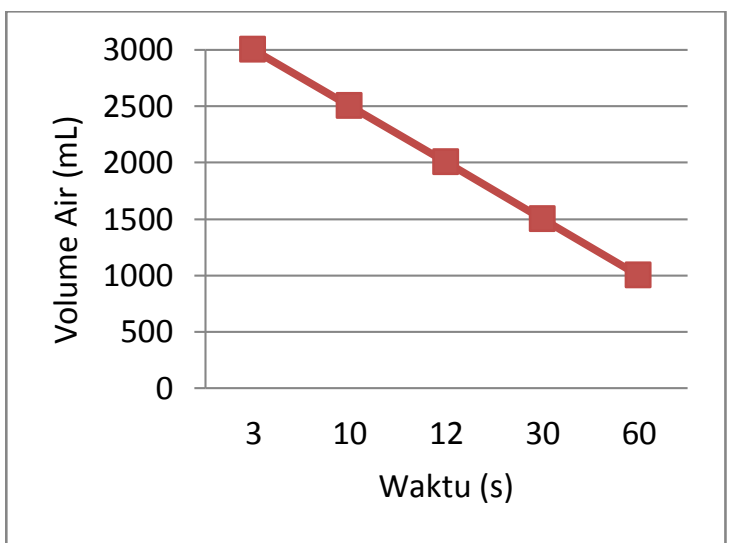

Gambar 4.2: Pengaruh volume air $(\mathrm{mL})$ terhadap waktu likuefaksi (s)

Dari grafik 4.2, dapat dilihat bahwa banyaknya volume air yang tercampur dalam tanah mempengaruhi cepatnya waktu likuefaksi terjadi. Semakin banyak air yang terkandung dalam tanah maka semakin cepat pula proses likuefaksi yang terjadi dalam hitungan detik. Hal ini terjadi karena air dengan volume yang besar menjadi lebih mudah mengalir pada aquifer sehingga pembuburan pada tanah lebih mudah dan cepat

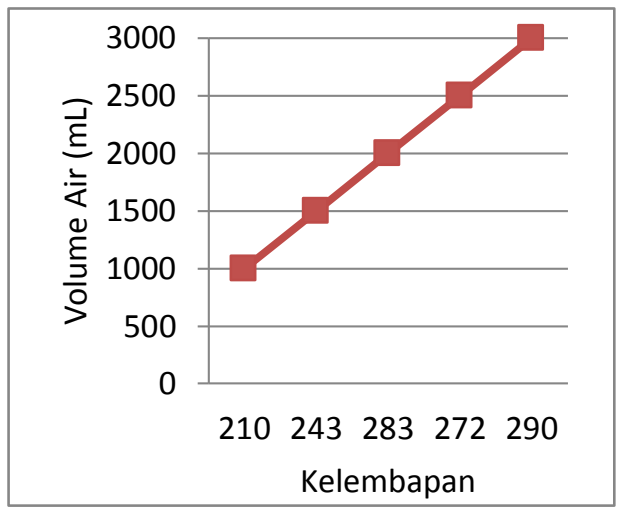

Gambar 4.3: Pengaruh volume air $(\mathrm{mL})$ terhadap nilai kelembapan pada ADC

Nilai yang dihasilkan pada ADC (Analog Digital Converter) sudah ditentukan sebagai berikut:

- 0-300: tanah basah (di dalam air)

- 300-700: tanah lembap 
- 700-950: tanah kering atau udara bebas

Dari grafik yang diatas, dapat diketahui bahwa pada percobaan 1-5 (tahap 1-5) terdapat kenaikan nilai kelembapan pada sensor yang tertanam pada tanah basah, dengan kata lain dapat dikatakan bahwa nilai volume air akan berbanding lurus dengan kelembapan. Pada percobaan ini (tanah basah), sensor membaca data kelembapan saat terjadi getaran yang memicu likuefaksi saat itu tanah dan air sudah tercampur sehingga nilai data analog dari output sensor kelembapan menunjukkan bahwa tanah basah.

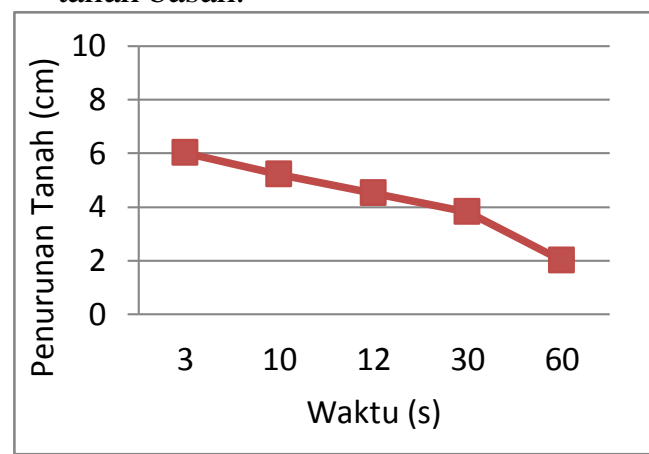

Gambar 4.4: Pengaruh waktu likuefaksi (s) terhadap penurunan tanah $(\mathrm{cm})$

Dari grafik yang menujukkan pengaruh waktu likuefaksi terhadap penurunan tanah dapat diambil kesimpulan bahwa semakin lama waktu yang diperlukan agar terjadi likuefaksi maka semakin sedikit pula penurunan tanah yang akan terjadi. Hal tersebut terjadi dikarenakan pada data yang memerlukan waktu yang lama agar terjadi likuefaksi memiliki volume air yang cenderung lebih sedikit sehingga campuran antara air dan tanahnya tidak lebih jenuh dari tanah yang mengandung volume air yang besar. Tanah yang jenuh merupakan salah satu tanah yang dapat memicu likuefaksi lebih cepat.

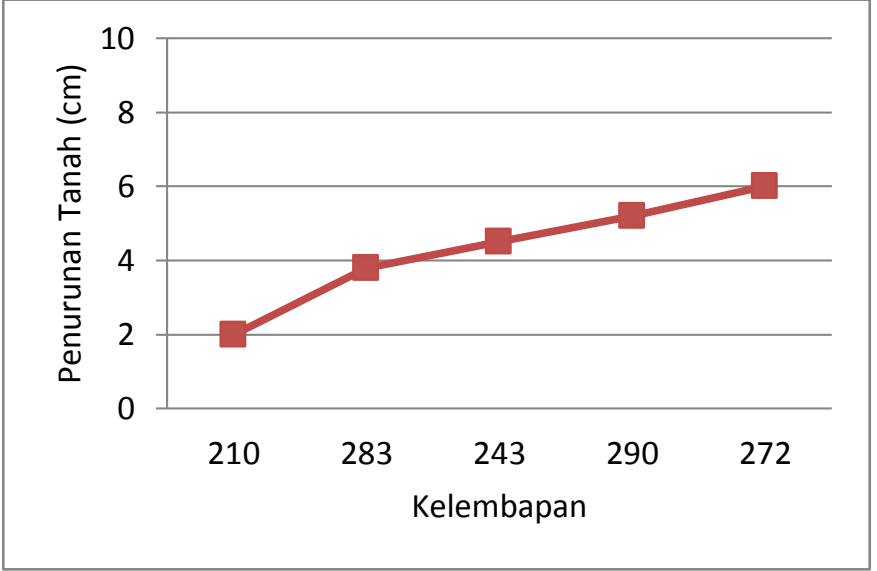

Gambar 4.5: Pengaruh nilai kelembapan pada ADC terhadap penurunan tanah $(\mathrm{cm})$

Nilai yang dihasilkan oleh ADC (Analog Digital Converter) pada sensor kelembapan diketahui memiliki nilai data sebagai berikut:

- 0-300: tanah basah (di dalam air)

- 300-700: tanah lembap

- 700-950: tanah kering atau udara bebas

Pada grafik diatas dapat dilihat bahwa nilai kelembapan yang hasilkan oleh ADC yang membaca nilai analog dari sensor kelembapan berpengaruh terhadap penurunan tanah. Semakin tinggi nilai kelembapan maka semakin besar pula penurunan tanah yang terjadi. Nilai kelembapan pada kelima data tersebut menunjukkan bahwa tanah basah karena sensor kelembapan membaca data ketika likuefaksi telah terjadi yaitu ketika tanah sudah bercampur dengan air sehingga tanah menjadi basah. Jika penurunan tanah besar, dapat dikatakan bahwa tanah tersebut memiliki nilai kelembapan yang cukup besar karena likuefaksi terjadi dengan mudah sehingga penurunan tanahnya besar.

\section{KESIMPULAN:}

Dari keseluruhan proses Rancang Bangun Alat Perekam Data Likuefaksi Berbasis Arduino Nano, maka dapat disimpulkan beberapa hal diantaranya: 
1. Sensor kelembapan berfungsi baik dengan nilai rata rata tegangan output sensor kelembapan untuk tanah kering lebih besar, dengan delapan tahapan pengambilan data yaitu $2,51 \mathrm{~V}$, sedangkan untuk kondisi tanah basah adalah $0,87 \mathrm{~V}$.

2. Rancang Bangun Alat Perekam Data Likuefaksi Berbasis Arduino Nano, berfungsi baik dalam pencatatan nilai suhu dan kelembapan tanah.

3. Rancang Bangun Alat Perekam Data Likuefaksi Berbasis Arduino Nano dapat digunakan untuk mencatat serta merekam data kejadian bencana likuefaksi. Serta digunakan untuk mempermudah untuk menganalisa potensi terjadinya likuefaksi didaerah tertentu dengan memanfaatkan sensornya untuk mengukur suhu tanah, kelembapan tanah, serta getaran yang terjadi pada tanah.

4. Hasil pengujian alat pada skala simulator (wadah yang terbuat dari plastik transparan) dapat bekerja dengan efektif karena data yang didapatkan menghasilkan kesimpulan bahwa volume air pada tanah berpengaruh pada nilai kelembapan dan waktu likuefaksi yang dihasilkan. Data tersebut akan otomatis tercatat apabila pada alat terjadi getaran yang diasumsikan sebagai gempa.

\section{DAFTAR PUSTAKA}

Akbar, A. 2017. Pengontrol Suhu Air Menggunakan Sensor DS18B20 Berbasis Arduino Uno [Tugas Akhir] Medan: Fakultas Matematika dan Ilmu Pengetahuan Alam, Universitas Sumatra Utara

Bahsan, E. 2018. Likuifaksi "Ngobrol sekitar gempa Lombok \& Palu" [Seminar] Jakarta: Departemen Teknik Sipil, Universitas Indonesia

Budiyanto, S. 2012. Sistem Logger Suhu dengan Menggunakan Komunikasi Gelombang Radio. Jurnal Teknik Elektro. Vol.3. No.1. ISSN 2086-9479
Lonteng, Christian Vicky Delfis. et al. 2013. Analisis Potesni Likuifaksi Di PT. PLN (PERSERO) UIP KIT SULMAPA PLTU 2 SULAWESI UTARA 2 X 25 MW POWER PLAN. Jurnal Sipil Statik. Vol.1. No.11. ISSN 2337-6732

Tandigala, Bartholomeus. 2019. Dampak Bencana Gempa Bumi, Likuifaksi, Tsunami Sulawesi Tengah [Seminar] Palu: Kalak BPBD Provinsi Sulawesi Tengah

Hazen, A. 1920. Hydraulic Fill Dams. Journal Paper. Vol.83. No.1. Pg. 1713-1745

Khairunnisa, A. 2018. Kareba Palu Koro. https://www.humanitarianresponse.info/ sites/www.humanitarianresponse.info/fil es/documents/files/karebapalu_dec_ii_e n_fnl.pdf

Ludman, A. 1993. Physical Geology. ISBN 0070115109. Mcgraw-Hill

Lufiyana, Hudallah Noor, Suryanto Agus. 2017. Rancang Bangun Alat Ukur Suhu Tanah, Kelembapan Tanah, dan Resistansi. Jurnal Teknik Elektro. Vol.9. No.2. ISSN 1411-0059

Najmurrokhman, et al. 2018. RANCANG BANGUN PROTOTIPE SISTEM INFORMASI KONDISI GEDUNG MERUPAKAN MIKROKONTROLER ARDUINO DAN MODUL GSM. Jurnal Teknik Elektro. Universitas Jendral Ahmad Yani. ISSN 2407-1846

Sinaulan, O. M., Sugiarso, B. A. 2015. Perancangan Alat Ukur Kecepatan Kendaraan Menggunakan ATMEGA 16. Jurnal Teknik Elektro dan Komputer. ISSN 2301-8402

Widyaningrum, R. 2012. Penyeliidikan Geologi Teknik Potensi Likuefaksi Daerah Palu,Provinsi Sulawesi Tengah.

Wijaya, H. W. 2017. Perancangan Alat Penyiram Tanaman Otomatis dengan YL-69 Berbasis Arduino Uno R3 [Naskah Publikasi]. Yogyakarta: Fakultas Ilmu Komputer, Universitas AMIKOM 
Djukarina. 2015. Arduino Nano.

https://djukarna4arduino.wordpress.com/201 5/01/19/arduino-nano [19 Januari 2015]

\section{LAMPIRAN}
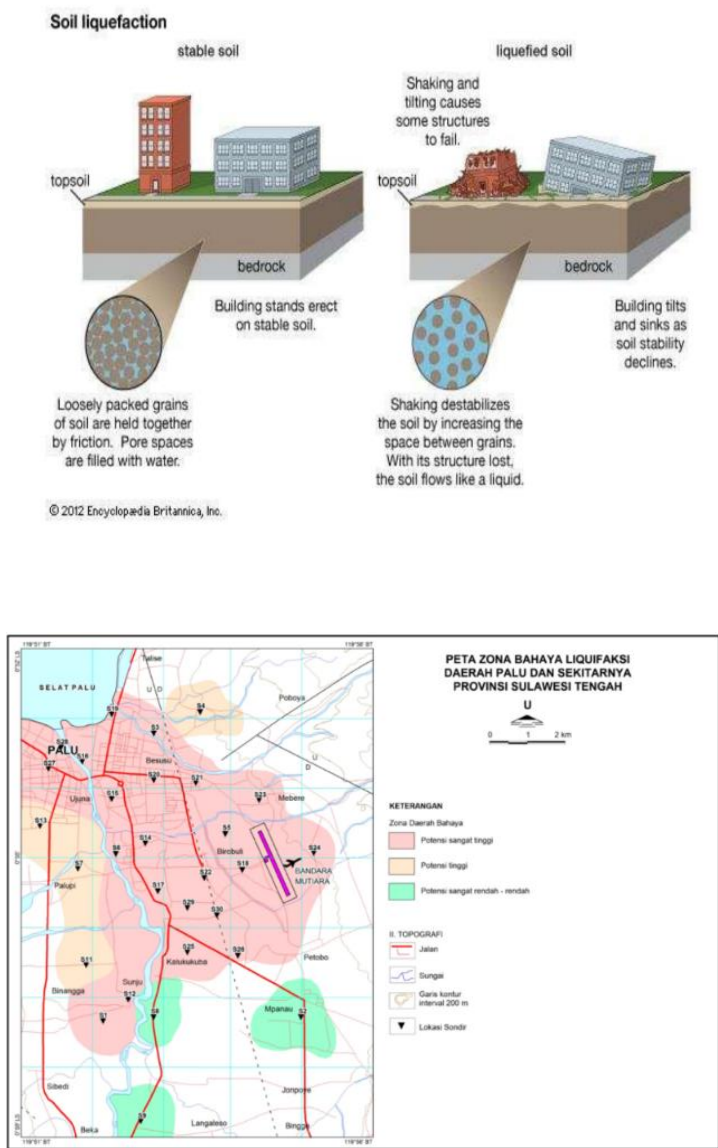

Lampiran 2: Peta zona bahaya likuefaksi daerah Palu (Widyaningrum, 2012)

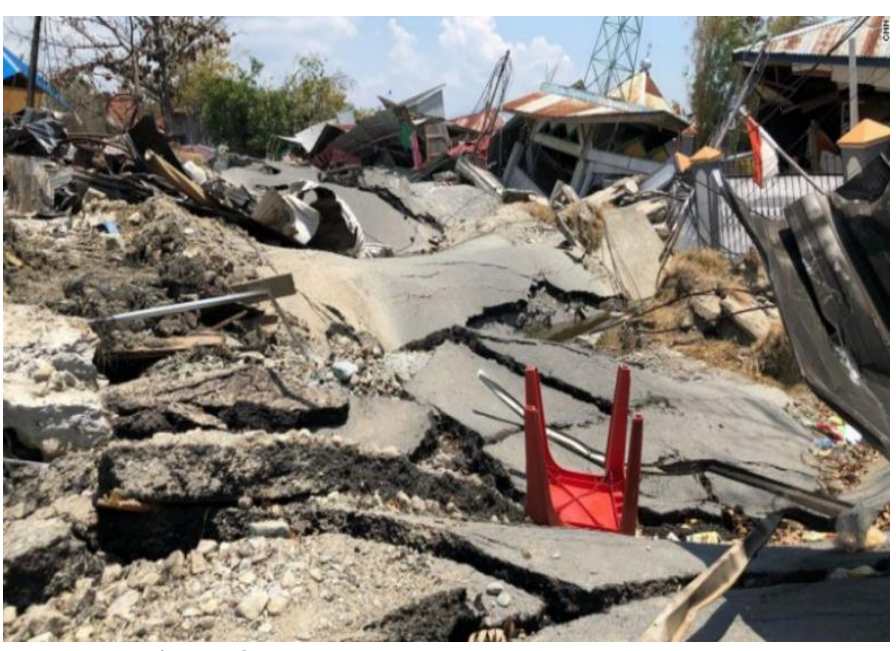

Lampiran 3: Likuefaksi Petobo, Sulawesi Tengah (Bahsan, 2018)

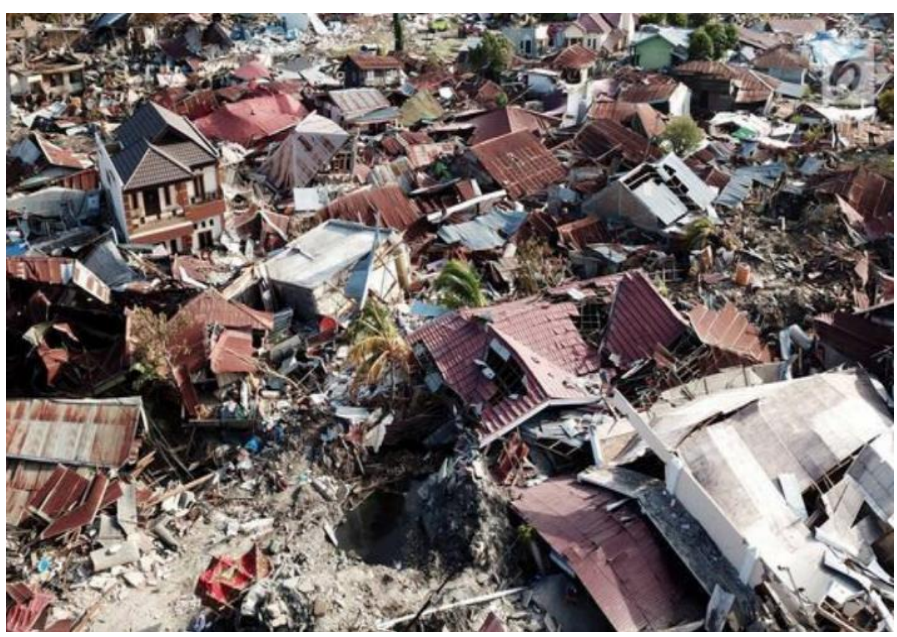

Lampiran 4: Likuefaksi Desa Balaroa, Sulawesi Tengah (Dr. Ir. Bartholomeus Tandigala, 2019) 